\title{
REVISTAS LATINOAMERICANAS DE ENFERMERÍA INDIZADAS EN SCOPUS
}

\author{
SCOPUS INDEXED LATIN AMERICAN NURSING JOURNALS
}

Julio Cjuno', Janina Bazalar Palacios ${ }^{2}$

\section{Sr. Editor}

La profesión de enfermería, se ve inmersa en el acelerado desarrollo de la humanidad en todos ámbitos, que amerita responder con calidad y conocimiento científico a las nuevas necesidades del cuidado de la persona. ${ }^{1}$ En ese sentido, la investigación permite obtener y generar conocimientos a través de la publicación de sus resultados de sus investigaciones en revistas científicas. ${ }^{2}$ Sin embargo, es poco valorada y experimentada por aquel profesional.

Los enfermeros(as) que se han desempeñado en la investigación, buscan revistas indizadas, ya que a través de ellas obtienen mayor calidad, factor de impacto (FI), cuartil en ranking SciMago, publicaciones internacionales, revisores internacionales, visibilidad y prestigio, puesto que ello incrementa la probabilidad de ser leídas y citadas en futuros artículos e investigaciones científicas. ${ }^{3}$ Por ese motivo, muchos de ellos prefieren publicar en revistas indizadas a Scopus,

1 Centro de Estudios Poblacionales, Uladech Católica. Correo electrónico: jcjunosuni@gmail.com

2 Enfermera, Instituto de Investigación de la Universidad Católica los Ángeles de Chimbote, Perú. 
siendo esta, una de las bases de datos de mayor calidad y prestigio a nivel mundial, pues contiene todas las revistas indizadas en MEDLINE y la colección más amplia de revistas latinoamericanas. ${ }^{4}$ Para ser parte de ella, las revistas científicas deben cumplir rigurosas evaluaciones. ${ }^{5}$

Ante lo expuesto, se realizó la búsqueda utilizando el portal de evaluación de revistas indizadas en Scopus (SCImago Journal \& Country Rank), seleccionando solo revistas de enfermería (Nursing in Latin America). Se identificó 13 revistas indizadas en Scopus, pertenecientes solo a 26,3\% (N=5) de 19 países que conforman América Latina. Además, se analizó cuantas revistas pertenecen a universidades, número de artículos publicados en el 2014, costo a autores o lectores y el idioma.

Encontramos que Brasil lidera la lista con siete revistas indizadas en Scopus, Venezuela y Chile continuaron con dos, y por último Colombia y México con una revista cada uno. Asimismo, 69,2\% (N=9) revistas publican diferentes artículos en inglés, español y portugués, y el 23,1\% ( $\mathrm{N}=3)$ publican el mismo artículo en español, portugués e inglés a la vez. El 69,2\% (N=9) revistas pertenecen a universidades y el resto a instituciones privadas y de gobierno y $30,8 \%(\mathrm{~N}=4)$ revista cobra a autores o lectores.

En la búsqueda realizada en febrero del 2017, se encontró que el 69,2\% de revistas publica en tres diferentes idiomas: inglés, español y portugués, esto posiblemente se debe a que la diversidad de idiomas implica mayor visibilidad. De igual manera, se encontró que la mayoría de revistas pertenecen a universidades, así también la mayoría no cobra a autores o lectores, a diferencia de revistas de otras regiones, quienes cobran por publicar o leer. Esto probablemente se debe a los escasos recursos económicos destinados a la investigación científica en América Latina; ante esta situación desfavorable, resulta lógico que solo las revistas financiadas por universidades logren subsistir (Ver tabla 1).

Los hallazgos expuestos indican que sería muy útil conocer la calidad de las publicaciones para saber si el problema sólo es el acceso o también la calidad de las publicaciones en las revistas de enfermería en América Latina. No obstante, esperamos haber logrado mejorar el conocimiento acerca de la realidad de revistas científicas indexadas en Scopus de Latinoamérica, además de saber, cual y como es el papel que cumplen estas en la investigación. 
Revistas de latinoamericanas de enfermería indizadas en Scopus

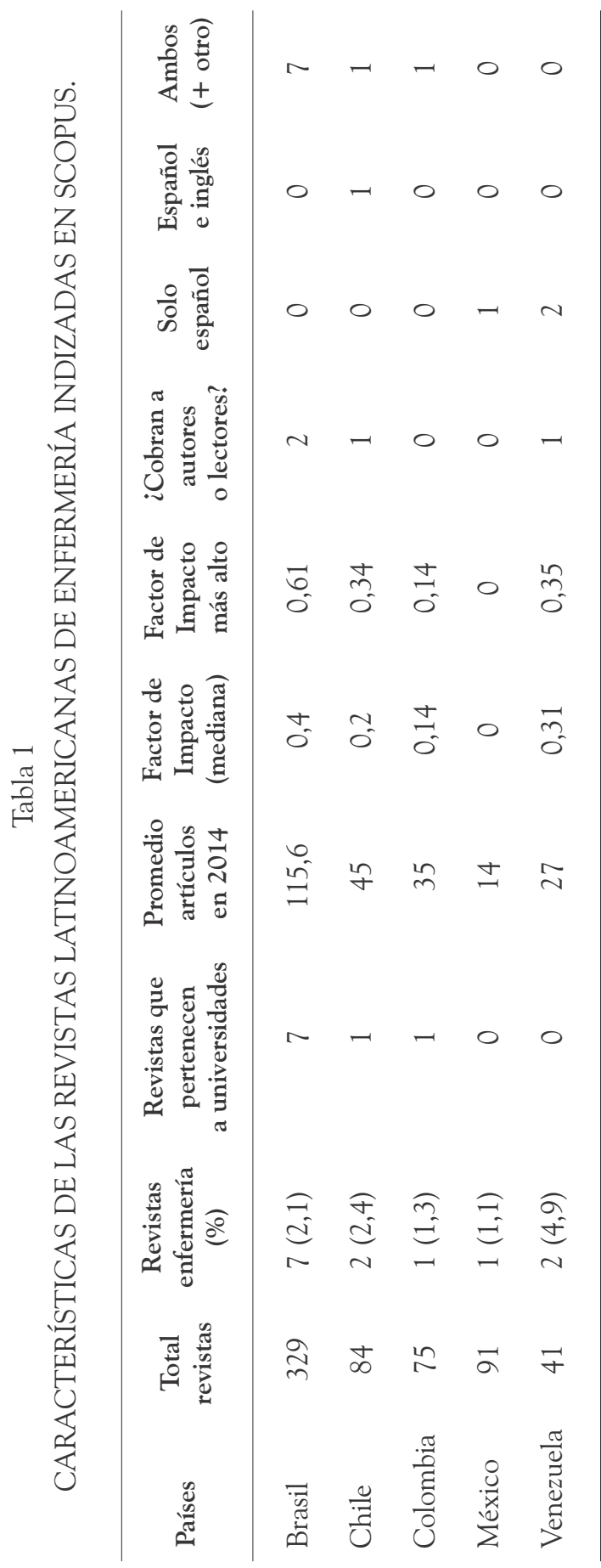




\section{REFERENCIAS BIBLIOGRÁFICAS}

1. Orellana Y, Sanhueza A. Competencia en investigación en Enfermería. Cienc Enferm. 2011;17:9-17.

2. Momen $\mathrm{H}$. The role of journals in enhancing health research in developing countries. Bull World Health Organ. 2004;82:163.

3. Balhara YPS. Indexed journal: what does it mean? Lung India. 2012;29(2):193.

4. Huamaní C, Romaní F, González-Alcaide G, Mejia MO, Ramos JM, Espinoza M, et al. South American Collaboration in Scientific Puplications on Leishmaniasis: Bibliometric Analisys in Scopus (2000-2011). Rev Inst Med trop S Paulo. 2014;56:381-90.

5. Cañedo Andalia R, Rodríguez Labrada R, Montejo Castells M. Scopus: la mayor base de datos de literatura científica arbitrada al alcance de los países subdesarrollados. Acimed. 2010;21(3):270-82. 